Editorial Manager(tm) for Physical Therapy Reviews Manuscript Draft

Manuscript Number: PTR-007-100R1

Title: The use of Pursed Lips Breathing in stable COPD: a systematic review of the evidence.

Article Type: Systematic Review

Keywords: Chronic Obstructive Pulmonary Disease; Dyspnoea; Physiotherapy; Pursed lips breathing; Systematic review

Corresponding Author: Ms Suzanne Roberts,

Corresponding Author's Institution: University of Hertfordshire

First Author: Suzanne Roberts

Order of Authors: Suzanne Roberts; Myra Stern; Fiona M Schreuder; Tim Watson

Abstract: Objective: A systematic review was carried out to determine the evidence for teaching pursed lips breathing (PLB) to patients with stable COPD. Exertional dyspnoea is the single most important factor limiting function for people with COPD and PLB is commonly advocated for its management. Method: A literature search of Medline, PEDro and CINAHL Plus was conducted. Articles were included if they studied the effects of PLB in stable COPD and excluded when proxy interventions or significant modifications of PLB were used. Where comparable data were available they were pooled using weighted means.

Results: Eleven studies involving 226 participants were included; four of the studies were of moderate quality according to The Grading of Recommendations Assessments, Development and Evaluation (GRADE) system, with the remaining studies being of low quality. Although no high quality evidence was identified, with the exception of one low quality study, the direction of effect for PLB was consistently towards benefit. Moderate quality evidence demonstrates that in stable COPD pursed lips breathing increases oxygen saturation and tidal volume, reduces respiratory rate during use at rest and reduces time taken to recover to pre-exercise breathlessness levels; one RCT showed reduction in exertional dyspnoea and improvement in functional performance at 3 months. Additionally, the evidence suggests that not all patients with COPD respond equally to PLB, those with moderate to severe COPD being most likely to benefit.

Conclusion: High quality studies are required to identify PLB responders from non-responders and to determine whether short-term effects translate into clinically significant benefit 
The use of Pursed Lips Breathing in stable COPD: a systematic review of the evidence

Roberts S, Stern M, Schreuder FM, Watson T

Address of the department or institute to which the work should be attributed:

School of Health and Emergency Professions

University of Hertfordshire

Hatfield

AL10 9AB

UK

Full postal address of each author:

Ms S Roberts (corresponding author)

Department of Physiotherapy

The Whittington Hospital NHS Trust

Magdala Avenue

London

N19 5NF

UK

Suzanne.roberts@whittington.nhs.uk

Tel: 02072885489

Fax: 02072885661

Dr M Stern

Department of Thoracic Medicine

The Whittington Hospital NHS Trust

Magdala Avenue

London

N19 5NF

UK

Mrs F. M. Schreuder

School of Health and Emergency Professions

University of Hertfordshire

College Lane

Hatfield

AL10 9AB

UK

Prof T Watson

School of Health and Emergency Professions

University of Hertfordshire

College Lane

Hatfield

AL10 9AB

UK 


\title{
The use of Pursed Lips Breathing in stable COPD: a systematic review of the evidence
}

\begin{abstract}
Objective: A systematic review was carried out to determine the evidence for teaching pursed lips breathing (PLB) to patients with stable COPD. Exertional dyspnoea is the single most important factor limiting function for people with COPD and PLB is commonly advocated for its management.
\end{abstract}

Method: A literature search of Medline, PEDro and CINAHL Plus was conducted. Articles were included if they studied the effects of PLB in stable COPD and excluded when proxy interventions or significant modifications of PLB were used. Where comparable data were available they were pooled using weighted means.

Results: Eleven studies involving 226 participants were included; four of the studies were of moderate quality according to The Grading of Recommendations Assessments, Development and Evaluation (GRADE) system, with the remaining studies being of low quality. Although no high quality evidence was identified, with the exception of one low quality study, the direction of effect for PLB was consistently towards benefit. Moderate quality evidence demonstrates that in stable COPD pursed lips breathing increases oxygen saturation and tidal volume, reduces respiratory rate during use at rest and reduces time taken to recover to pre-exercise breathlessness levels; one RCT showed reduction in exertional dyspnoea and improvement in functional performance at 3 months. Additionally, the evidence suggests that not all patients with COPD respond equally to PLB, those with moderate to severe COPD being most likely to benefit.

Conclusion: High quality studies are required to identify PLB responders from nonresponders and to determine whether short-term effects translate into clinically significant benefit

Keywords: Chronic Obstructive Pulmonary Disease; Dyspnoea; Pursed lips breathing; Physiotherapy; Systematic review

\section{Introduction}

Chronic Obstructive Pulmonary Disease (COPD) is recognised as a major cause of morbidity and mortality world wide (1). Nearly 20 years ago COPD was recognised as the fifth greatest cause of disability in the world and it has been predicted that it will be the third commonest cause of death worldwide by 2020 (2, 3). In 1999 COPD accounted for 5\% of all deaths in the UK and by 2004900,000 people, in the UK, had a diagnosis of COPD and half as many again were thought to be living with the condition undiagnosed (4). The most frequent and disabling complaint of people with COPD is exertional breathlessness; this is often the primary reason people with COPD seek medical help. Exertional breathlessness, also referred to as exertional dyspnoea is breathlessness triggered by physical exertion where the degree of breathlessness reported is disproportionate to the physical exertion undertaken (5). Exertional dyspnoea is the single most important factor limiting function on a day-to-day basis with progression of COPD being associated with increasing exertional dyspnoea, which may extend to dyspnoea at rest, and worsening quality of life $(2,6,7)$. 
Pursed lips breathing (PLB) is a breathing retraining strategy, adopted spontaneously by some patients, that has also been advocated for the treatment of dyspnoea (5). It is customarily integrated into pulmonary rehabilitation programmes for the management of exertional dyspnoea in COPD (8-10). PLB is carried out by exhaling through partially closed lips i.e. through pursed lips as if making the flame of a small candle flicker. It has also been described as "moderately active expiration through half opened lips" with reported mean expiratory mouth pressures of $5 \mathrm{cmH} 2 \mathrm{O}$ being generated (11).

The role of PLB however is not without controversy; it is reported as possibly reducing the discomfort associated with dyspnoea, either through alteration in the breathing pattern and gaseous exchange or by subjective means but also labelled as a dysfunctional breathing pattern $(12,13)$. With this in mind the literature for PLB was reviewed to ascertain the quality of evidence, indications, and effects of PLB when used in the management of patients with stable COPD. The Grading of Recommendations Assessments, Development and Evaluation (GRADE) system followed assesses both the quality of evidence and the balance of benefits and harms. It has been adopted by a number of national and international organisations including the World Health Organisation, the American Thoracic Society and the Cochrane Collaboration among others (14-17). The GRADE system classifies quality of evidence as High, Moderate, Low or Very Low with the option to amalgamate the last two categories. High quality evidence is defined as being such that "further research is very unlikely to change our confidence in the estimate of effect", moderate quality evidence as "further research is likely to have an important impact on our confidence in the estimate of effect and may change the estimate" and low quality evidence as "further research is very likely to have an important impact on our confidence in the estimate of effect and is likely to change the estimate" (16).

\section{Methods}

Literature Search: The databases Medline, PEDro and CINAHL Plus were searched for English language papers containing "pursed lip breathing" and "pursed lips breathing" in the title or abstract. Search criteria excluded children and animal studies. Studies were also excluded from further consideration if they were performed on healthy volunteers, did not have stable COPD as the patient population, used proxy interventions or significant modifications of PLB, or were not original research. The papers cited as references in each paper were also identified for relevance. The proxy interventions and modified PLB identified and excluded were the use of expiratory resistive loading to mimic PLB and manual assistance in addition to PLB.

Assessment of Published Studies: Studies identified were assessed using the Grading of Recommendations Assessments, Development and Evaluation (GRADE) system (14-17). Initially an explicit statement of the question to be addressed was framed: "What is the effect of teaching pursed lips breathing to patients with stable COPD?" and then the papers identified in the literature search were reviewed firstly for relevance in answering this question and then with regard to study design and methodology. In particular, method of allocation to groups, blinding, loss to follow-up and power to detect effect, using National Institute of Health and Clinical Excellence (18) taxonomy and methodology checklists were considered. The studies providing 
the highest quality evidence were looked at in detail and results of lower quality studies looked at to assess consistency of effect.

Where comparable data were available they were pooled using weighted means. The weighted mean was used in order to combine mean values from comparable studies with different sample sizes but still represent all the individual scores equally. The weighted mean was derived by multiplying the mean of each study by its sample size, summing these, then divided by the total number of participants in all studies.

Finally a summary of findings based on the evidence, including the balance of desirable and undesirable effects, likely variability of patient response and the extent to which the intervention represents a good use of resources was made.

\section{Results}

Available Literature: The initial database search identified 54 papers. PLB is variously lengthened as pursed lips, pursed-lips, pursed lip and pursed-lips breathing; searching on pursed lips breathing returned the most complete results. Following exclusion of studies identified by more than one search engine nine were relevant (1927 ) and two further studies were identified from the reference list of these nine studies $(28,29)$.

Study design: All 11 studies were prospective studies with subjects chosen to participate in a planned trial with identified outcome measures in order to answer a pre-specified research question or hypothesis. Ten studies addressed the short-term effects of PLB. The remaining study (25) looked at the effects of PLB over 12 weeks. All studies made a comparison between groups; two were randomised controlled trials $(25,27)$, the remainder compared different interventions to the same group of patients over time.

Quality of Literature: None of the 11 studies identified fulfilled all the stated criteria for a high quality study with regard to randomisation, blinding to allocation, comparison with control group or sufficient trial size to ensure power to detect effect however four studies of moderate quality were identified $(22,23,25,27)$; the remaining studies were of low quality. Table 1 summarises these findings.

Effects of PLB on oximetry, tidal volume and respiratory rate at rest: PLB, used at rest in subjects with stable COPD, has positive short-term effects on oximetry, tidal volume and respiratory rate. Four studies reported on the effects of PLB on oximetry seven on tidal volume and nine on respiratory rate, with at least one of the studies in each case being of moderate quality. Not all the studies reported gave raw data and therefore range or standard deviation could not be calculated however results reported here were statistically significant. Two studies $(28,29)$ accounting for 19 subjects $(7$ and 12 respectively) gave results significant to $\mathrm{p}<0.5$ with the remaining studies having a significane of at least $<0.05$.

Training with oximetry feedback resulted in a mean increase in oxygen saturation of $4.5 \%$, from a baseline of $91.1 \%$, a mean increase in tidal volume of 0.600 millilitres and a mean reduction in respiratory rate of 7.2 breaths per minute (27). Pooling the comparable data from all available studies resulted in similar findings: a reduction in 
respiratory rate of 6.6 breaths per minute, an increase in tidal volume of 500 millilitres and an increase in oxygen saturation of $2.5 \%$. Table 2 summarises these findings.

Effects on respiratory rate and tidal volume on exercise: Only one study, of moderate quality, reported on the effects of PLB used by subjects with stable COPD during maximal exercise and in the recovery period after exercise. This study demonstrated beneficial short-term effects on recovery time (22). PLB used during the incremental shuttle walk test (ISWT) and during the recovery period resulted in a mean reduction in end exercise respiratory rate of 6.2 (95\% confidence intervals $4.5-$ 7.9) breaths per minute and a mean reduction in recovery time of 25 (95\% confidence intervals $2.8-47$ ) seconds, that is $12 \%$. There was no change in ISWT distance (22).

Two low quality studies $(24,26)$ considered the effects of PLB on respiratory pattern during sub-maximal exercise protocols and showed a reduction in respiratory rate and an increase in tidal volume. Both of these studies provided sufficient raw data to show the range of subject response; this was considerable. Reduction in respiratory rate using PLB varied from 0 to 20 breaths per minute and increase in tidal volume from 10 millilitres to +996 millilitres. These findings are summarised in Table 3 .

Effects on work of breathing: PLB has been shown to cause a shift in inspiratory muscle work from the diaphragm to the intercostal muscles when compared to resting breathing (28). Compared to resting breathing, one study of moderate quality showed PLB is associated with lower oxygen consumption (23) and a further, low quality study showed statistically significant improvement in arterial blood gases despite reduced minute ventilation: reduction in $\mathrm{PaCO} 2$ of $0.59 \mathrm{kPa}$ and increase in $\mathrm{PaO} 2$ of $0.43 \mathrm{kPa}(24)$.

Effects on dyspnoea: The impact of PLB on dyspnoea remains uncertain. Five studies identified consider the impact of PLB on dyspnoea. Breathlessness was measured in a variety of ways with Borg perceived breathlessness scale (30) being the most frequently used outcome measure. All studies investigated dyspnoea experienced by populations of stable COPD subjects either during every day activities or during specific periods of exercise and as such can be said to relate to exertional dyspnoea. Of these five studies only one was of moderate quality. From the pooled data $40 \%$ of COPD subjects can be predicted to report relief from dyspnoea using PLB in these circumstances. This is summarised in Table 4. Relief from dyspnoea when using PLB correlates most strongly with the ability of PLB to reduce endexpiratory lung volumes $(19,26)$. From the individual studies, use of PLB was variously shown to result in: a $12 \%$ reduction in recovery time from dyspnoea after maximal exercise as measured by Borg perceived breathlessness scale and respiratory rate in 48 subjects (22), self-reported relief of dyspnoea in 7 out of 12 subjects (24), reduction in breathlessness in 19 the out of 30 subjects as measured by Borg perceived breathlessness scale (19), a worsening in 4, no change in 2 and improvement in 2 of 8 subjects for breathlessness as measured by visual analogue scale during sub-maximal exercise (26), no change in breathlessness at rest as measured by Borg perceived breathlessness scale in 12 subjects (28).

Recently optoelectronic plethysmography has been used to evaluate changes in chest wall compartment volumes, to assess whether the volume changes of the chest wall can help identify the reason why some patients benefit from PLB and others do not. 
Thirty patients with COPD were studied and two distinct patterns of breathing that were adopted when instructed to use PLB were identified (19). The 19 most severely obstructed and hyperinflated patients increased their tidal volume (mean 630mls) by decreasing the end-expiratory volumes of the chest wall and abdomen. The remaining 11 patients increased their tidal volume (mean $360 \mathrm{mls}$ ) but this was associated with an increase in end-expiratory volume i.e. overall hyperinflation. Whilst the first group reported a reduction in breathlessness using PLB the second group did not. The subjects that demonstrated no worsening hyperinflation and a mean reduction in Borg score using PLB had a mean FEV1 \% predicted of $38 \%+/-13$ i.e. moderate to severe COPD (31). The subjects that demonstrated worsening hyperinflation and no mean change in Borg score using PLB had a mean FEV1\% predicted of 56\% +/- 14 i.e. mild COPD.

Medium-term effects: A 4-week PLB teaching programme resulted in reduced breathlessness on 6-minute walk test and improved health related quality of life at 12 weeks (25). The randomised controlled 3-limb study compared a 4-week intervention of PLB, expiratory muscle training or education (control) in 40 subjects with stable COPD. Significant improvement was only shown in the PLB limb, with a mean reduction of 0.9 in Borg scores at the end of 6 minute walk and mean increases in SF36 physical function domain of 16 .

Method of teaching PLB: Studies vary in the detail given regarding teaching PLB with seven of the studies reviewed giving some details. Where detail is provided these have been summarised in Table 5. Of particular note the inspiratory to expiratory ratio encouraged can be seen to vary considerably from 1:2 to 1:4 or more and the use of oximetry biofeedback is detailed in only 2 studies $(25,27)$.

Direction of effect: Despite evidence from any trial fulfilling all the stated criteria for a high quality study the direction of effect towards benefit from PLB, with the exception of one study (26), was consistent.

\section{Discussion}

Review of the literature and application of the GRADE system to studies of the effects of PLB in stable COPD suggests that PLB is safe and that there is moderate quality evidence to support its use in clinical practice.

Study design: The main concerns with regard to study design were insufficient power to draw sustainable conclusions, poor randomisation and lack of blinding. For PLB, blinding of participants and those delivering the intervention is not possible however those assessing and analysing the outcome could have been blinded to allocation. This is a pre-requisite for a high quality randomised controlled trial.

Effects on dyspnoea: The stated purpose of teaching PLB is the relief of dyspnoea however the impact on this symptom remains the most uncertain. As reported in the results all studies reviewed for this paper that reported directly on dyspnoea were investigating the impact of PLB on exertional dyspnoea in stable COPD. The 1970's study by Mueller et al (24) reported 7 of 12 subjects gaining relief from dyspnoea when using PLB and highlights the observation in clinical practice that, whilst some patients report considerable benefit from PLB, others do not. In 2007, for the first 
time, the work by Bianchi et al (19) demonstrated clear differences between PLB responders and non-responders. Benefit from PLB was demonstrated only in those with moderate to severe COPD. From the data presented here $40 \%$ of COPD subjects can be predicted to benefit from PLB but this is an amalgamation of response rates varying from zero to $63 \%$ and may reflect the varying severity of COPD in subjects studied.

These two sub-groups of COPD patients, the PLB responders and non-responders, would appear to be a strong confounding factor in trials to date with non-responders reducing the power to detect benefit in responders.

Teaching PLB in clinical practice: Another possible explanation for the wide variation in PLB response rate may be variation in methods for teaching PLB. The logistics and resources required in clinical practice remain inconclusive with variations in reported practice, or practice not fully described. The most effective means of teaching PLB and the need for oximetry feedback during learning has not yet been established, neither has the extent and number of follow up visits required to establish effective PLB in the clinical setting and to achieve effective carry over into daily life.

Clinical Significance of findings: Regardless of statistical significance, having identified that PLB provides the possibility of reducing respiratory rate by nearly 7 breaths per minute, increasing tidal volumes by $500 \mathrm{mls}$ and improving oxygen saturations by $2.5 \%$ these clinically significant changes might be expected to result in appreciable day-to-day benefit for patients and this is supported by an improved recovery rate from exercise induced breathlessness (22). When these short-term benefits are experienced over a longer period in everyday life this may then translate into longer-term benefits in the form of improved functional performance. The improvement in SF-36 Physical Functioning scale of 16 points reported by Nield et al (25) is likely to be clinically significant; 23 points has been reported as the impact of a chronic medical condition on everyday physical function (32) and 10.5 as a change recognized by the general population as indicating "much better" (33).

\section{Conclusion}

The evidence to date suggests that for a sub-group of patients with stable COPD, PLB has 3 areas of effects: during use at rest PLB training with oximetry biofeedback increases oxygen saturation and tidal volume whilst reducing respiratory rate; when used during exercise and in the recovery period after exercises it reduces the recovery time of breathlessness; when taught over 4 weeks, PLB reduces exertional dyspnoea and improves functional performance as measured at 3 month follow-up.

Based primarily on the 3 clinical studies of best quality evidence $(22,25,27)$ it would be reasonable to attempt to teach PLB using oximetry biofeedback to stable COPD patients within existing care delivery programmes such as pulmonary rehabilitation programmes. Respiratory rate and oxygen saturations should be recorded during quiet breathing and during PLB at rest with advice given to the patient dependent on the observed response. Where respiratory rate falls and oxygen saturation increases with PLB the patient should be advised to practise PLB at rest on a daily basis and to try using it during activities that normally make them breathless or to speed their 
recovery when they have become breathless. Where no positive response is observed it should be explained to the patient that this is a technique that seems to help some patients more than others and they may or may not benefit from it. Daily practise, as before, for 4 weeks can be trialled with a low threshold for discontinuing use if no benefit is seen.

Whilst this review has demonstrated there is reason to expect PLB to have a role in the symptomatic management of stable COPD further high quality studies are required to determine how to stratify patients into PLB responder and non-responders both for research purposes and for clinical practice. In addition the focus of future research should aim to replicate medium term effects and identify long-term effects of PLB in clinical practice including using outcome measures to capture benefit in dyspnoea, exercise endurance and health related quality of life outcomes. 
Table 1: Design and methodological features for PLB studies reviewed

\begin{tabular}{ccccl}
\hline \multicolumn{5}{c}{ Reported } \\
Comparison & Randomisation & Blinding & Power & Ref \\
\hline Control & $\checkmark$ & x & $\checkmark$ & $(25)^{*}$ \\
group & $\checkmark$ & $\checkmark$ & x & $(27)^{*}$ \\
\hline Same & $\checkmark$ & $\checkmark$ & $\checkmark$ & $(22)^{*}$ \\
Group & $\checkmark$ & x & $\checkmark$ & $(22,23)^{*}$ \\
over time & $\checkmark$ & x & x & $(19,24,26)$ \\
& $x$ & $x$ & $x$ & $(20,21,28$, \\
& & & & $29)$ \\
\hline
\end{tabular}

* Studies assessed as moderate quality according to GRADE system definitions 
Table 2: Effects of PLB in stable COPD, used at rest

\begin{tabular}{|c|c|c|c|c|}
\hline & $\begin{array}{l}\text { No of } \\
\text { studies }\end{array}$ & $\begin{array}{l}\text { Total } \\
\text { number of } \\
\text { subjects }\end{array}$ & $\begin{array}{l}\text { Weighted } \\
\text { mean }\end{array}$ & Refs \\
\hline $\begin{array}{l}\text { Respiratory } \\
\text { rate }\end{array}$ & 9 & 138 & $-6.6 \mathrm{bpm}$ & $\begin{array}{l}(19-21,23,24,26- \\
29)\end{array}$ \\
\hline Tidal Volume & 7 & 103 & $+500 \mathrm{mls}$ & $(19,20,24,26-29)$ \\
\hline $\begin{array}{l}\text { Oxygen } \\
\text { saturation* }\end{array}$ & 4 & 49 & $+2.5 \%$ & $(21,24,27,28)$ \\
\hline
\end{tabular}


Table 3: Effect of PLB in stable COPD, used during exercise

\begin{tabular}{|c|c|c|c|c|}
\hline & $\begin{array}{l}\text { No of } \\
\text { studies }\end{array}$ & $\begin{array}{l}\text { Total } \\
\text { number of } \\
\text { subjects }\end{array}$ & Weighted mean & Refs \\
\hline $\begin{array}{l}\text { RR on sub- } \\
\text { maximal ex }\end{array}$ & 2 & 19 & $\begin{array}{l}-6.98 \mathrm{bpm} \\
\text { (range } 0 \text { to }-20 \mathrm{bpm} \text { ) }\end{array}$ & $(24,26)$ \\
\hline $\begin{array}{l}\text { TV on sub- } \\
\text { maximal ex }\end{array}$ & 2 & 19 & $\begin{array}{l}+270 \mathrm{mls} \\
\text { (range }-10 \text { to } 996 \mathrm{mls} \text { ) }\end{array}$ & $(24,26)$ \\
\hline
\end{tabular}


Table 4: Proportion of COPD patients reporting benefit from PLB

\begin{tabular}{lll}
\hline $\begin{array}{l}\text { \% PLB responders } \\
\text { (weighted mean) }\end{array}$ & $\begin{array}{l}\text { Total number } \\
\text { of subjects }\end{array}$ & Refs \\
\hline $\begin{array}{l}40 \% \text { responders } \\
\text { Range } 0-63 \%\end{array}$ & 110 & $(19,22,24,26,28)$ \\
\hline
\end{tabular}


Table 5: Information provided from seven studies on PLB technique and application

\begin{tabular}{ll}
\hline PLB instructions & $\begin{array}{l}\text { "Normal" breath in through nose, out through pursed lips } \\
\text { avoiding forceful exhalation, or similar }(19-22,25-27)\end{array}$ \\
\cline { 2 - 2 } & Breath out for twice as long as breath in $(27)$ \\
\cline { 2 - 2 } & Breath out for as long as you comfortably can (25) \\
\cline { 2 - 2 } $\begin{array}{l}\text { Additional } \\
\text { information }\end{array}$ & $\begin{array}{l}\text { 4 hospital } 3 \text { to } 4 \text { times as long as breath in }(22) \\
10 \text { min/day for the first week increasing to } 25 \text { min/day in } \\
\text { frequent short practices by the fourth week (25) }\end{array}$ \\
\hline $\begin{array}{l}\text { Co-ordinate walking and breathing so that you breathe in for } \\
\text { one stride and out for 2 (25) }\end{array}$ \\
$\begin{array}{l}\text { Whilst learning subjects instructed to observe oximeter with } \\
\text { aim of increasing saturations }(25,27)\end{array}$ \\
\hline
\end{tabular}




\section{References:}

(Key references indicated by $*$ )

1. Nishimura K, Izumi T, Tsukino M, Oga T. Dyspnea is a better predictor of 5year survival than airway obstruction in patients with COPD. Chest. 2002 May;121(5):1434-40.

2. Barberger-Gateau P, Tessier J, Nejjari C. Dyspnoea and disability: An epidemiological approach. Crit Rev Phys Rehabil Med. 1997;9(3\&4):265-99. 3. Lopez AD, Murray CC. The global burden of disease, 1990-2020. Nat Med. 1998 Nov;4(11):1241-3.

4. National Institute for Health and Clinical Excellence. Chronic obstructive pulmonary disease. National clinical guideline on management of chronic obstructive pulmonary disease in adults in primary and secondary care. Thorax. 2004 Feb;59 Suppl 1:1-232.

5. American Thoracic Society. Dyspnea. Mechanisms, assessment, and management: a consensus statement. American Thoracic Society. Am J Respir Crit Care Med. 1999 Jan;159(1):321-40.

6. Eltayara L, Becklake MR, Volta CA, Milic-Emili J. Relationship between chronic dyspnea and expiratory flow limitation in patients with chronic obstructive pulmonary disease. Am J Respir Crit Care Med. 1996 Dec;154(6 Pt 1):1726-34.* 7. Mahler DA. Dyspnoea in chronic obstructive pulmonary disease. Monaldi Arch Chest Dis. 1998;53(6):669-71.

8. British Thoracic Society. Pulmonary rehabilitation. Thorax. 2001 Nov;56(11):827-34.

9. Chartered Society of Physiotherapy. The effectiveness of pulmonary rehabilitation: evidence and implications for physiotherapists; 2003.

10. Nici L, Donner C, Wouters E, Zuwallack R, Ambrosino N, Bourbeau J, et al. American Thoracic Society/European Respiratory Society statement on pulmonary rehabilitation. Am J Respir Crit Care Med. 2006 Jun 15;173(12):1390-413.

11. Van der Schans CP, De Jong W, Kort E, Wijkstra PJ, Koeter GH, Postma DS, van der Mark ThW. Mouth Pressures during pursed lip breathing. Physiother Theory Pract. 1995; 11:29-34.

12. Hough A. Physiotherapy in Respiratory Care. 3rd ed. Cheltenham: Nelson Thornes Ltd; 2001. p. 173

13. Innocenti DT, Troup F. Dysfunctional breathing. In: Pryor JP, Prasad SA, editors. Physiotherapy for Respiratory and Cardiac Problems. $4^{\text {th }}$ ed. London: Churchill Livingstone; 2008. p. 545.

14. Guyatt GH, Oxman AD, Kunz R, Falck-Ytter Y, Vist GE, Liberati A, et al. Going from evidence to recommendations. BMJ. 2008c May 10;336(7652):1049-51.

15. Guyatt GH, Oxman AD, Kunz R, Vist GE, Falck-Ytter Y, Schunemann HJ. What is "quality of evidence" and why is it important to clinicians? BMJ. 2008b May 3;336(7651):995-8.

16. Guyatt GH, Oxman AD, Vist GE, Kunz R, Falck-Ytter Y, Alonso-Coello P, et al. GRADE: an emerging consensus on rating quality of evidence and strength of recommendations. BMJ. 2008a Apr 26;336(7650):924-6.

17. Schunemann HJ, Jaeschke R, Cook DJ, Bria WF, El-Solh AA, Ernst A, et al. An official ATS statement: grading the quality of evidence and strength of recommendations in ATS guidelines and recommendations. Am J Respir Crit Care Med. 2006 Sep 1;174(5):605-14. 
18. National Institute for Health and Clinical Excellence. The guidelines manual. London: National Institute for Health and Clinical Excellence; 2007.

19. Bianchi R, Gigliotti F, Romagnoli I, Lanini B, Castellani C, Binazzi B, et al. Patterns of chest wall kinematics during volitional pursed-lip breathing in COPD at rest. Respir Med. 2007 Jul;101(7):1412-8.

20. Bianchi R, Gigliotti F, Romagnoli I, Lanini B, Castellani C, Grazzini M, et al. Chest wall kinematics and breathlessness during pursed-lip breathing in patients with COPD. Chest. 2004 Feb;125(2):459-65.

21. Breslin EH. The pattern of respiratory muscle recruitment during pursed-lip breathing. Chest. 1992 Jan;101(1):75-8.

22. Garrod R, Dallimore K, Cook J, Davies V, Quade K. An evaluation of the acute impact of pursed lips breathing on walking distance in nonspontaneous pursed lips breathing chronic obstructive pulmonary disease patients. Chron Respir Dis. 2005;2(2):67-72.

23. Jones AY, Dean E, Chow CC. Comparison of the oxygen cost of breathing exercises and spontaneous breathing in patients with stable chronic obstructive pulmonary disease. Phys Ther. 2003 May;83(5):424-31.

24. Mueller RE, Petty TL, Filley GF. Ventilation and arterial blood gas changes induced by pursed lips breathing. J Appl Physiol. 1970 Jun;28(6):784-9.

25. Nield MA, Soo Hoo GW, Roper JM, Santiago S. Efficacy of pursed-lips breathing: a breathing pattern retraining strategy for dyspnea reduction. J Cardiopulm Rehabil Prev. 2007 Jul-Aug;27(4):237-44.

26. Spahija J, de Marchie M, Grassino A. Effects of imposed pursed-lips breathing on respiratory mechanics and dyspnea at rest and during exercise in COPD. Chest. 2005 Aug;128(2):640-50.

27. Tiep BL, Burns M, Kao D, Madison R, Herrera J. Pursed lips breathing training using ear oximetry. Chest. 1986 Aug;90(2):218-21.

28. Roa J, Epstein S, Breslin EH, Shannon T, Celli BR. Work of breathing and ventilatory muscle recruitment during pursed lip breathing in patients with chronic airway obstruction. Am Rev Respir Dis. [Abstract only - conference proceedings]. 1991;143:A77.

29. Thoman RL, Stoker GL, Ross JC. The efficacy of pursed-lips breathing in patients with chronic obstructive pulmonary disease. Am Rev Respir Dis. 1966 Jan;93(1):100-6.

30. Wilson RC, Jones PW. A comparison of the visual analogue scale and modified Borg scale for the measurement of dyspnoea during exercise. Clin Sci (Lond). 1989 Mar;76(3):277-82.

31. The National Collaborating Centre for Chronic Conditions. Chronic Obstructive Pulmonary Disease. National clinical guideline on management of chronic obstructive pulmonary disease in adults in primary and secondary care: Diagnosing COPD. Thorax. 2004; 59.(Suppl 1): i27-i38.

32. McHorney CA, Ware JE, Jr., Raczek AE. The MOS 36-Item Short-Form Health Survey (SF-36): II. Psychometric and clinical tests of validity in measuring physical and mental health constructs. Med Care. 1993 Mar;31(3):247-63.

33. Garratt AM, Ruta DA, Abdalla MI, Russell IT. SF 36 health survey questionnaire: II. Responsiveness to changes in health status in four common clinical conditions. Qual Health Care. 1994 Dec;3(4):186-92. 
Comments from the Editors and Reviewers - response

\section{The use of Pursed Lips Breathing in stable COPD: a systematic review of the evidence}

Reviewer \#1: The concept of the systematic review is a good one and will be of great interest to physiotherapists working with the population with COPD.

There are some features of the review that should be adapted in order to improve its accuracy:

Title, abstract and text

The author uses the term "Pursed Lips Breathing" - whereas literature commonly referred to used the term "pursed lip breathed" or "pursed-lip breathing". No capitals are required and it is recommended that the author applies one of the two more commonly used phrases throughout the manuscript.

RESPONSE: I chose pursed lips breathing as my impression from the literature was that this was the more internationally used term although in clinical practice (England) my colleagues and I use pursed lip breathing. From a review of the search terms pursed lips breathing returns the most complete search results and therefore I would prefer to continue with pursed lips breathing.

\section{Introduction}

Paragraph 1- the author should revise the reference and statement referring to developed countries to include all countries. WHO data clearly state that COPD is a health priority in all countries. The references used in the next section $(2 \& 3)$ refer to data from 1997 and 1998 and should be updated to reflect the most recent prevalence statistics.

RESPONSE: Regarding developed countries/all countries I agree with the comment and have changed the sentence. Regarding prevalence data the reviewer is correct that the prevalence data comes from 97/98; I searched the WHO data carefully and could not find more recent worldwide prevalence data but the following sentences bring the data more up to with the aim of showing this continues to be a significant problem.

The author should describe what they mean by the term dyspnoea - it is not clear whether they are using it synonymously with "exertional dyspnoea" but if so that is technically incorrect.

RESPONSE: defined in intro and specified in results on dyspnoea

In paragraph 2 the author quotes a description of the PLB technique (ref 11) but does not quote a page reference.

RESPONSE: Ref 11 is a journal ref and includes pgs 29-34 but as outlined below was an incomplete reference that has now been updated 
In paragraph 3 refs 12 and 13 are texts but there is no link to chapters in the texts.

RESPONSE: ref 12 is not a multi-authored book therefore referencing had followed advice to contributors however I have now added the relevant page number as for multi-authored book. Ref 13 is a multi-authored book so have amended the reference accordingly

The GRADE system is described in this paragraph and again in paragraphs $2 \& 3$ of the method - . it would be better to include the details of the ranges here and delete the description in the methods section.

RESPONSE: changed as suggested

Methods

Paragraph 3 - data are plural

RESPONSE: agree, changed as suggested

Results

Paragraph 1 - write numbers $<10$.

RESPONSE: agree, changed as suggested

Paragraph 3. The findings are summarised in Table 1."

It would be helpful if each of the sections that follow is introduced in a standardised way indicating the number of papers included and the level of evidence

RESPONSE: I have tried to address the points made here without making the text un-necessarily cumbersome. Information on number of papers studied included.

Paragraph $4 \mathrm{lt}$ is not clear from the text how many studies were included here. Paragraph $5 \mathrm{lt}$ is not clear from the text how many studies were included here.

RESPONSE: Inclusions to Para's 4 and 5 made to address above points

Paragraph 6 There are a few changes in wording required to improve accuracy e.g. PLB does not generate changes in pleural pressure.

RESPONSE: Attempt to clarify meaning of sentence on pleural pressure by focusing on implication

Paragraph 7 - Suggest using the term pooled rather than amalgamated. In this section is the author referring to the weighted mean. Reference the Borg scale as well as the manuscripts under discussion. 
RESPONSE: both points addressed

Paragraph 8 Correct the format of the Bianchi reference; Clarify the reference to FEV 1 of $38 \%$ being moderate to severe COPD

RESPONSE: Bianchi ref corrected, reference to COPD severity included

\section{Discussion}

The discussion should start with an overarching paragraph about the outcomes of the systematic review. The conclusion includes some statements that could be used earlier in the discussion

RESPONSE: intro to discussion included

Are there any other factors to be discussed that may influence whether subjects are responders and non responders besides severity of respiratory function e.g. airway pathology?

RESPONSE: based on evidence reviewed it is not possible to draw other conclusions

Table 1 - title - it is only the studies included not all the ones that were identified that are referred to in the table

RESPONSE: corrected

Table 2 was the arterial oxygen saturation peripheral?

RESPONSE: predominantly peripheral oximetry - note to table added In light of comment below I have included sentence on statistical significance (not all papers give raw data therefore could not analyse further)

Table 3 spell out the words in the table or else have a code underneath it what were the standard deviations and ranges?

RESPONSE: code included, however does feel a bit like stating the obvious. Raw data was given in these two papers so I have included ranges

Table 4 include number of studies in the title; what was the standard deviation?

RESPONSE: Inclusion of references identifies that this relates to 5 studies. I do not think clarity would be improved by adding "in 5 studies" to title; but can do if felt essential. Standard deviation - the variation of measures used, as indicated in the text, means it would not be appropriate to try to identify standard deviation hence the decision to include range of response reported by the different studies to indicate this is a very variable outcome 
Table 5 change practise to practice; suggest layout change to more clearly identify the number of studies referenced.

RESPONSE: my understanding was when practice/practise refers to an activity e.g. practising swimming or in this case practising PLB the correct spelling was with an "s" and so have left it as "s" but happy to be guided by editor. Spelt with a "c" when referring to clinical practice. Number of studies included in title.

\section{References}

There are a number of errors in the list e.g. some journals are abbreviated and others not; no chapter references with texts; no contract or document numbers for reference 17; incomplete referencing 11 , need to spell out come abbreviations e.g. ATS Indicate what the asterisk refers to as it is not coded anywhere.

RESPONSE: Referencing errors corrected. Regarding asterisk: from notes for contributors "Please indicate the 3-10 most important references clearly (e.g. by an asterisk)." I assumed the journal format would therefore indicate the reason for asterisks but have added a line at the beginning of the references in case not. 